\title{
Effect of platelet rich plasma in diabetic foot healing
}

\author{
Daniela MIRICESCU ${ }^{1}$, Alexandra TOTAN ${ }^{1}$, \\ Constantin STEFANI ${ }^{2,3}$, Ana Maria Alexandra STANESCU ${ }^{2}$, loana Ruxandra RUSU ${ }^{4}$, \\ Maria GREABU ${ }^{1}$ \\ ${ }^{1}$ Department of Biochemistry, Faculty of Dental Medicine, \\ "Carol Davila" University of Medicine and Pharmacy, Bucharest, Romania \\ 2Department of Family Medicine, "Carol Davila" University of Medicine and Pharmacy, \\ Bucharest, Romania \\ 3"Carol Davila" University Central Emergency Military Hospital, Bucharest, Romania \\ ${ }^{4}$ Department of Anatomy, "Carol Davila" University of Medicine and Pharmacy, \\ Bucharest, Romania
}

\begin{abstract}
PRP (platelet rich plasma) is a natural source of growth factors obtained from the patient's blood which are involved in the wound healing process. PRP therapy is successfully applied in the medical field, being used nowadays in diabetic patients who develop as complication the diabetic foot. The purpose of this review is to present the composition of PRP growth factors, PRP preparation stages and the results obtained in patients diagnosed with diabetic foot.
\end{abstract}

Keywords: platelet rich plasma, diabetic food, healing process

\section{INTRODUCTION}

PRP is an autologous biological product that is obtained from the patient's blood following a centrifugation process. This endogenous therapeutic produs is increasingly used in regenerative medicine due to its potential to stimulate and accelerate the healing process. PRP growth factors are polypeptide substances that regulates cell growth, proliferation, differentiation and metabolism for different cell types $(1,2)$. PRP promotes endothelial and epithelial regeneration, stimulates angiogenesis, collagen synthesis, homeostasis and soft tissue healing (3).

In a healthy person the normal number of platelets varies between 150,000 and 350,000 cells/ $\mu \mathrm{l}$ of blood. Platelets are small, discoid, nucleus-free cells that are formed in the bone mar- row (from megakaryocytes), cannot reproduce and have a lifespan of about 7-10 days. Platelets are involved in hemostasis and coagulation. When bleeding occurs, platelets are activated and release growth factors that stimulate the inflammatory cascade and healing process. Proteins and other biomolecules are secreted by three types of granules (alpha, delta and lambda) located inside the platelets. $\alpha$ granules are the most abundant, representing $10 \%$ of platelet volume $(50-80 \alpha$ granules per platelet) and secretes over 300 soluble proteins $(4,5)$.

These proteins are involved in coagulation, inflammation, cell growth, cell adhesion, and immune function, as follows:

- Adhesive proteins: fibrinogen, laminin-8, trombospondin-1, trombospondin-2, Von Willebrand factor 
- Growth factors: platelet-derived growth factor (PDGF), epidermal growth factor (EGF), fibroblastic growth factor (FGF), insulin-like growth factor (IGF), endothelial vascular growth factor (VEGF), transforming growth factor (TGF- $\beta$ ), keratinocyte growth factor (KGF)

- Angiogenic factors: VEGF, FGF, TGF- $\beta$

- Chemokines: IL-8, MIP-1 $\alpha$ (macrophage inflammatory proteins-1 $\alpha$ ), MIP-2, MCP-1 (monocyte chemoattractant protein-1)

- Clotting factors and their inhibitors: factor $\mathrm{V}$, antithrombin, factor IX, factor S, protease nexin-1, protease nexin-2

- Integral membrane proteins: integrins, immunoglobulin family receptors, platelet endothelial cell adhesion molecules

- Immune mediators: IgG, complement C3 and $\mathrm{C} 4$ precursors, factor $\mathrm{D}$, factor $\mathrm{H}, \mathrm{C} 1$ inhibitor $(4,6)$.

Delta granules contain biomolecules that stimulate the coagulation process (calcium, magnesium, adenosine) but also bioactive amines, such as serotin and histamine (6). Lambda granules contain enzymes for the degradation of proteins, lipids and carbohydrates, being involved in the removal of damaged tissue fragments and infectious agents. PRP contains growth factors released from platelet $\alpha$ granules (7-10).

\section{STAGES OF WOUND HEALING}

The wound healing process is a dynamic one and includes the following phases:

- hemostasis

- inflammatory response

- cell proliferation, reepithelialization, granulation and angiogenesis

- matrix remodeling and scar formation

Immediately after skin injury, platelets are stimulated to aggregate themselves to form the fibrin clot and recruitment of different cell types. Growth factors, cytokines and other hemostasis-specific factors are activated during the first phage. The inflammatory stage is characterized by the release of histamine, serotonin, bioactive factors that lead to the arrival of inflammatory cells at the site of injury such as neutrophils, leukocytes and macrophages. Neutrophils with the help of macrophages are involved in the prevention of bacterial infections and activates keratinocytes, fibroblasts and immune cells. At the end of the inflammatory phase, the macrophages release growth factors that will be involved in the third stage of wound healing. Extracellular matrix remodeling is a complex process that includes the participation of cytokines, growth factors, which promote cell migration, epithelialization, adhesion and wound contraction (11).

\section{THE ROLE OF GROWTH FACTORS IN THE WOUND HEALING PROCESS}

Currently, PDGF is approved in USA by the FDA (Food and Drug Adminstration) and European Authority for clinical applications in patients. Is one of the first growth factors that are secreted after injury, promoting many metabolic processes such as collagen and protein synthesis, chemotaxis of fibroblasts and smooth muscle cells, as well as collagenase activity $(9,12)$. PDGF present angiogenic effects promoting the proliferation and migration of endothelial cells.

It can stimulate the production of TGF- $\beta$ which initiates the synthesis of coalgen, but also the production of IGF $(9,12)$. PDGF present strong chemotactic effects on neutrophils, monocytes, smooth muscle cells, promoting mitosis of fibrobalts, smooth muscle cells and endothelial cells. This growth factor stimulates the process of angiogenesis, wound contraction, granulation tissue formation and finally wound remodeling. PDGF is secreted in the proliferative stage of wound healing. In addition to platelets, macrophages, keratinocytes, endothelial cells and muscle cells can secrete PDGF (9-12).

EGF is involved in the epithelialization phase of wound healing, being synthesized by platelets, fibroblasts, macrophages and mesenchymal stem cells. Plays a vital role in proliferation, differentiation, growth and migration of epithelial and keratinocyte cells $(13,14)$.

Macrophages, endothelial cells, fibroblasts, $T$ lymphocytes and mast cells secrete FGF, being involved in the proliferative phase of wound healing ( in re-epithelialization, angiogenesis) (15). It stimulates fibroblast proliferation, collagen accumulation and accelerates the formation of the granulation tissue (16). IGF is implicated in the proliferative and inflammatory phase of wound healing, being secreted by fibroblasts on which it exerts autocrine effects. IGF in combination with PDGF promotes keratinocyte maturation, enhancing tissue repair $(17,18)$.

VEGF is secreted by platelets, fibroblasts, macrophages and keratinocytes, is active in the proliferative phase of wound healing. VEGF present paracrine effects on endothelial cells, is the main growth factor promoting granulation tissue angiogenesis $(19,20)$.

TGF- $\beta$ growth factors family, includes 3 isoforms: TGF- $\beta 1, T G F-\beta 2$ and TGF- $\beta 3$ which are in- 
volved in different stages of wound healing. Are secreted by platelets, macrophages, T lymphocytes, endothelial cells, fibroblasts, muscle cells and keratinocytes. TGF- $\beta 1$ and TGF- $\beta 2$ are present in the inflammatory phase, TGF- $\beta 3$ is active in the remodeling phase of the wound healing process $(21,22)$. TGF- $\beta 3$ is involved in the angiogenesis process, and the first 2 isoforms in fibrosis and scarring. These growth factors promote differentiation of myoblasts and fibroblasts, extracellular matrix formation, wound contraction and finally wound healing (23). KGF is present in the epithelialization of the healing process, inducing keratinocyte proliferation and migration $(16,17)$.

\section{PRP PRODUCTION}

Currently, there are many different commercial products, capable of obtaining PRP from the patient's blood usually through two centrifugation processes. After the first centrifuge, the red blood cells will be separated from the plasma and will be found in the bottom of the centrifuge container. Above the erythrocytes layer, buffy coat of white blood cells is formed, platelets will have the highest concentration in plasma just above the buffy coat $(24,25)$.

\section{PRP PREPARATION STAGES}

- Blood collection: around $30 \mathrm{ml}$ of venous blood is collected into tubes containing sodium citrate anticoagulant to prevent platelet activation

- First stage of centrifugation: the blood is first centrifuged with reduced forces (soft rotation from $200 \mathrm{~g}$ to $600 \mathrm{~g}$ ): three layers are separated: the upper layer containing platelets and white blood cells called platelet-poor plasma (PPP); an intermediate thin layer rich in white blood cells; and the bottom layer containing most of the red blood cells

- Second stage of centrifugation: takes place at a higher speed (hard rotation from $700 \mathrm{~g}$ to 2,300 g) to concentrate platelets: soft pellets (erythrocytes-platelets) are obtained at the bottom of the tube; the lower one-third of the tube which contains around $5 \mathrm{~mL}$ of plasma is homogenised by gently shaking to create PRP (26).

\section{PRP THERAPY AND DIABETIC FOOT TREATMENT}

Diabetes is a global health problem, both in developing and developed countries, considering that by 2030 there will be 366 million diabetic patients. One of the most serious complications of diabetes is the diabetic foot, most often leading to foot amputation $(27,28)$.

To test PRP effects on diabetic subjects, many studies were performed on laboratory diabetic animals. Clinical and experimental studies in animals or humans have reported that VEGF accelerates wound healing by increasing epithelialization, angiogenesis and granulation tissue formation (2931).

Nashwa Fathy El-Tahawy et al. conducted a study on diabetic male albino rats. The purpose of the study was to test PRP effects on the endocrine pancreas. PRP injections were administrated twice a week for 3 weeks in a dose of $0.5 \mathrm{mg} / \mathrm{kg}$. The results of the study showed the regeneration of pancreatic islets of the albino rats in response to PRP therapy (32). Navid Hosseini Mansoub et al. tested the effect of PRP therapy on burn diabetic rats. The results of the study confirm the beneficial effects of PRP therapy by healing burn injuries (33).

Babei $V$ et al. conducted a clinical trial between 2011 and 2014, which included 150 patients with diabetic foot, who received PRP therapy. Diabetic foot was completely healed after 8.8 weeks and after 8 months of PRP treatment, none of the wounds reopened (34).

A prospective study conducted by Singh SP et al. between 2013 and 2015, which included 29 patients with diabetic foot, who received PRP therapy, reported complete healing of diabetic patients after $36.7 \pm 3$ days compared with $60.6 \pm 3.7$ days in the control group. No side effects have been reported due to PRP therapy (35).

By 2018, around eleven clinical trials have been performed in patients with diabetic foot to test PRP therapy. All eleven studies reported diabetic foot healing without side effects after PRP administration. The healing period reported by these clinical trials was between $7.8 \pm 2.7$ and $8.3 \pm 3.7$ weeks (36).

\section{CONCLUSIONS}

PPR can be regarded as a cocktail of growth factors that are involved in different stages of the healing process, with positive results in the medical field. The incidence of diabetes has increased alarmingly in the population worldwide, which present many complications. PRP therapy for diabetes mellitus started first on laboratory animals, and then extended to diabetic patients.

All clinical studies performed still new on diabetic foot patients following PRP therapy reported 
complete healing between 7 to 8 weeks. The clinical studies performed did not report any side effects following PRP administration.

\section{Acknowledgement}

All authors equally contributed to the present paper.

\author{
Conflict of interest: none declared \\ Financial support: none declared
}

\section{REFERENCES}

1. Anitua E, Alkhraisat $\mathrm{MH}$, Orive $\mathrm{G}$. Perspectives and challenges in regenerative medicine using plasma rich in growth factors. J Control Release 2012; 157:29-38.

2. Kobayashi E, Flückiger L, FujiokaKobayash $L$ et al. Comparative release of growth factors from PRP, PRF, and advanced-PRF. Clin Oral Investig 2016; 20(9):2353-2360

3. Foster TE, Puskas BL, Mandelbaum BR et al. Platelet-rich plasma: From basic science to clinical applications. Am J Sports Med 2009; 37: 2259-2272.

4. Maynard DM, Heijnen HF, Horne MK, et al. Proteomic analysis of platelet alphagranules using mass spectrometry. J Thromb Haemost 2007 5:1945-195.

5. Coppinger JA, Cagney G, Toomey S et al. Characterization of the proteins released from activated platelets leads to localization of novel platelet proteins in human atherosclerotic lesions. Blood 2004; 103:2096-2104.

6. Jedlitschky G, Tirschmann K, Lubenow LE et al. The nucleotide transporter MRP4(ABCC4) is highly expressed in human platelets and present in dense granules, indicating a role in mediator storage. Blood 2004; 104:3603-3610.

7. Falanga V. Wound healing and its impairment in the diabetic foot. Lancet 2005; 366: 1736-1743.

8. Koveker GB. Growth factors in clinical practice. Int J Clin Pract 2000; 54:590-593.

9. Rossi LA, Murray IR, Chu CR et al. Classification systems for platelet-rich plasma. Bone Joint J 2019; 101-B(8):891-896.

10. Arwert EN, Hoste E, Watt FM. Epithelial stem cells, wound healing and cancer. Nat Rev Cancer 2012; 12:170-180.

11. Lin PH, Sermersheim M, Li H et al. Zinc in Wound Healing Modulation. Nutrients 2018; 10(16):1-20.

12. Lynch SE, Nixon JC, Colvin R et al. Role of platelet-derived growth factor in wound healing: Synergistic effects with other growth factors. Proc Natl Acad Sci USA 1987; 84:7696-7700.

13. Girdler NM, McGurk M, Aqual S et al. The effect of epidermal growth factor mouthwash on cytotoxic-induced oral ulceration. A phase I clinical trial. Am J Clin Oncol 1995; 18:403-406.

14. Anitua E, de la Fuente M, Muruzabal F et al. Plasma rich in growth factors (PRGF) eye drops stimulates scarless regeneration compared to autologous serum in the ocular surface stromal fibroblasts. Exp Eye Res 2015;135:118-26.

15. Xie J, Bian H, Qi S et al. Effects of basic fibroblast growth factor on the expression of extracellular matrix and matrix metalloproteinase-1 in wound healing. Clin Exp Dermatol 2008; 33:176-182.

16. Enoch S, Grey JE, Harding KG. Recent advances and emerging treatments. $\mathrm{Br}$ Med J 2006; 332:962-965.

17. Haase I, Evans R, Pofahl, R et al. Regulation of keratinocyte shape, migration and wound epithelialization by IGF-1- and EGF-dependent signalling pathways. J Cell Sci 2003; 116: 3227-3238.

18. Greenhalgh DG, Hummel RP, Albertson S et al. Synergistic actions of platelet-derived growth factor and the insulin-like growth factors in vivo. Wound Repair Regen 1993; 1: 69-81.

19. Werner S, Grose R. Regulation of wound healing by growth factors and cytokines. Physiol Rev 2003; 83: 835-870.

20. Hsu C, Chang J. Clinical implications of growth factors in flexor tendon wound healing. J Hand Surg 2004; 29: 551-563.

21. Barrientos S, Stojadinovic O, Golinko MS et al. Growth factors and cytokines in wound healing. Wound Repair Regen 2008; 16:585-601.

22. Zielins ER, Atashroo DA, Maan ZN et al. Wound healing: An update. Regen Med 2014; 9:817-830.

23. Penn JW, Grobbelaar AO, Rolfe KJ. The role of the TGF-beta family in wound healing, burns and scarring: A review. Int $J$ Burns Trauma 2012; 2:18-28.

24. Boswell SG, Cole BJ, Sundman EA et al. Platelet-rich plasma: A milieu of bioactive factors. Arthroscopy 2012:28:429-439.

25. Marques LF, Stessuk T, Camargo IC et al. Platelet-rich plasma (PRP): methodological aspects and clinical applications. Platelets 2015; 26:101-113.

26. Dragoo JL, Braun HJ, Durham JL et al. Comparison of the acute inflammatory response of two commercial platelet-rich plasma systems in healthy rabbit tendons. Am J Sports Med 2012; 40:1274-1281.

27. WHO. Global report on diabetes from World Health Organization 2016; 21: 10-61.

28. Patel D, Kumar R, Laloo D et al. Diabetes mellitus: An overview on its pharmacological aspects and reported medicinal plants having antidiabetic activity. Asian Pac J Trop Biomed 2012; 2:411-420.

29. Galiano RD, Tepper OM, Pelo CR et al. Topical vascular endothelial growth factor accelerates diabetic wound healing through increased angiogenesis and by mobilizing and recruiting bone marrow-derived cells. Am J Pathol 2004;164:1935-1947.

30. Karayannopoulou M, Papazoglou, LG, Loukopoulos $P$ et al. D. Locally injected autologous platelet-rich plasma enhanced tissue perfusion and improved survival of long subdermal plexus skin flaps in dogs. Vet Comp Orthop Traumatol 2014; 27:379-386.

31. Penn JW, Grobbelaar AO, Rolfe KJ. The role of the TGF-beta family in wound healing, burns and scarring: A review. Int J Burns Trauma 2012; 2:18-28.

32. El-Tahawy NF, Rifaai RA, Saber EA al. Effect of platelet rich plasma (PRP) injection on the endocrine pancreas of the experimentally induced diabetes in male albino rats: A histological and immunohistochemical study. J Diabetes Metab 2017; 8:3.

33. Mansoub NH, Mehmet Gürdal M, Karadadaş $E$ et al. The role of PRP and adipose tissue-derived keratinocytes on burn wound healing in diabetic rats. Biolmpacts 2018; 8(1): 5-12.

34. Babaei V, Afradi H, Gohardani HZ et al. Management of chronic diabetic foot ulcers using platelet-rich plasma. $J$ Wound Care 2017; 2;26(12):784-787.

35. Singh SP, Kumar V, Pandey Aet al. Role of platelet-rich plasma in healing diabetic foot ulcers: A prospective study. J Wound Care 2018; 2,27(9):550-556.

36. Takashi Hirase, Eric Ruff, Salim Surani. Topical application of platelet-rich plasma for diabetic foot ulcers: A systematic review. World J Diabetes 2018; 9(10):172-179. 